\title{
A value based evaluation method for Product/Service System using design information
}

\author{
Tomohiko Sakao and Mattias Lindahl
}

\section{Linköping University Post Print}

N.B.: When citing this work, cite the original article.

Original Publication:

Tomohiko Sakao and Mattias Lindahl, A value based evaluation method for Product/Service System using design information, 2012, CIRP annals, (61), 1, 51-54.

http://dx.doi.org/10.1016/j.cirp.2012.03.108

Copyright: Elsevier

http://www.elsevier.com/

Postprint available at: Linköping University Electronic Press

http://urn.kb.se/resolve?urn=urn:nbn:se:liu:diva-79776 


\title{
A value based evaluation method for Product/Service System using design information
}

\author{
Tomohiko Sakao, Mattias Lindahl \\ Department of Management and Engineering, Linköping University, Sweden \\ Submitted by Jan-Gunnar Persson (1), Stockholm, Sweden.
}

This article proposes a new method for evaluating Product/Service System (PSS). It improves formulation of an evaluation step within an existing comprehensive method for designing PSS. The evaluation is achieved based on the importance of various customer value and each offering's contribution to the value as well as the customer's budget. Its advantage is the effective utilization of design information accumulated at the earlier part of the comprehensive method, as opposed to marketing oriented methods solely for utility measurement (e.g. conjoint analysis). Application of the entire method to a real life case at an investment machine manufacturer is presented.

Design method, Service, Evaluation

\section{Introduction}

In traditional product sales, the focus is often on developing products that are cheap to manufacture and enable a profitable aftermarket consisting of service, spare parts and consumables. However, manufacturers in developed countries today regard services as crucial and service activity is increasingly being incorporated into the design space. An offering from such design is often called Industrial Product-Service Systems (IPS ${ }^{2}$ ) or Product/Service Systems (PSS) [1]. PSS offerings (PSSO) consist of combinations of physical products, services and systems that have been integrated and optimized from a lifecycle perspective in relation to the customer value (modified from [1]).

At present, companies typically have a minor degree of integration between their physical product and service development, and the service development is done after the product is ready for realization, or even after it has been put on the market. This is the case even though it is well known that the physical product's design has a limiting impact on the service design. This sequence creates the problem of specifications transferred 'over the wall' as was addressed in the case of design and then manufacture [2]. In contrast to the sequential offering development, PSS demands a new way of developing an offering real integrated and parallel development. To achieve this, new methods are needed since traditional ones in general provide only minor support for integrated and parallel development of products and services. This method should support identification of PSSO requirements. In addition, support for PSSO concept development (generation and combination of products and services) and for effective and efficient evaluation of those concepts is needed. Especially for companies providing a wide variety of PSSOs, support for systematic evaluation is essential in order to ensure that their offering complies with the value perceived by customers.

There exist a few methods that support PSS design (e.g. [3][4][5][6][7]). Especially for the evaluation part of design, a method [8] can be utilized which has been developed by extending the QFD (Quality Function Deployment) technique [9] to PSS design. This method [8] reveals which parameters of a PSS should be focused on to efficiently meet customers' requirements.
In designing traditional physical products (e.g. [10]), some methods have been developed for concept selection. However, no methods are available to support the effective and efficient evaluation and selection of PSS concepts.

Motivated by the gap above, this article aims at proposing a new method for evaluation and selection of PSSOs. Instead of developing a completely new method, it improves formulation of a step for evaluation and selection within an existing and verified comprehensive method for designing PSS [6].

In the remainder of this article, Section 2 analyses literature and points out the lack of an effective method to evaluate PSS. Section 3 explains the proposed method after introducing the comprehensive PSS design method. Section 4 shows application of the whole method in an early phase of developing PSS at a manufacturer. Finally, Sections 5 and 6 discuss and conclude the article, respectively.

\section{PSS design and evaluation}

Traditional methods for designing physical products (e.g. [10]) contain some methods for evaluating and selecting a concept. Such methods, e.g. rating multiple concepts with multiple criteria, can be partly used for PSS. However, in the case of PSS, it is common to realize a set of various concepts as components within one PSSO; thus, selecting multiple concepts should be supported in such a method. At the same time, this selection is to be done with economic constraint. This means that the question is which multiple components should be selected against a certain budget of a customer. It is different from the case of physical product design, where a major question is which single structure should be chosen to fulfil a certain function. A component here means a potential part that could constitute a PSSO and is a product, a service, or a combination of the two. This issue has not been brought up explicitly in the PSS area. If a component is fundamental and cannot be ruled out, that component is seen as a platform and this selection process can be seen as customization [11]. However, no such methods are seen in that area, either.

To bridge this gap, there is a need for developing such a method for evaluating and choosing PSS components for a PSSO. Importantly, this evaluation should be done in terms of value 
perceived by customers (including users and other relevant actors), as value is the thing pursued by customers. Perceived value can be defined as the customer's overall assessment of the utility of a PSSO based on perceptions of what is received and what is given (based on [12]) and is different from a price; value depends on a particular user/customer. It should not be forgotten that a global PSS design method should partly address such information (as some methods such as [6][8] do), and thus collecting the needed information from scratch at the step of evaluation is not necessarily required.

From the marketing discipline, some methods are available for this purpose. For instance, conjoint analysis [13] discovers utility levels of elements in an offering. Disadvantages of conjoint analysis include all the additional efforts after design as well as a limitation on the number of elements addressed in an analysis.

In sum, developing a method for evaluating and choosing PSS components for offerings in terms of value, considering a certain budget by using design information, would be an interesting challenge from the scientific and practical viewpoints.

\section{A value based PSS evaluation method}

\subsection{Comprehensive PSS design method}

The entire method depicted by Figure 1 has been verified in [6] but lacks concrete formulation of a step for evaluation and selection (Step 7). The entire method takes customer value (CV) with its relative importance (Step 4) as inputs and translates it into the relative importance of PSS characteristics (Step 5) by extending the QFD technique. Importantly, different types of design information are obtained by carrying out this method prior to Step 7.

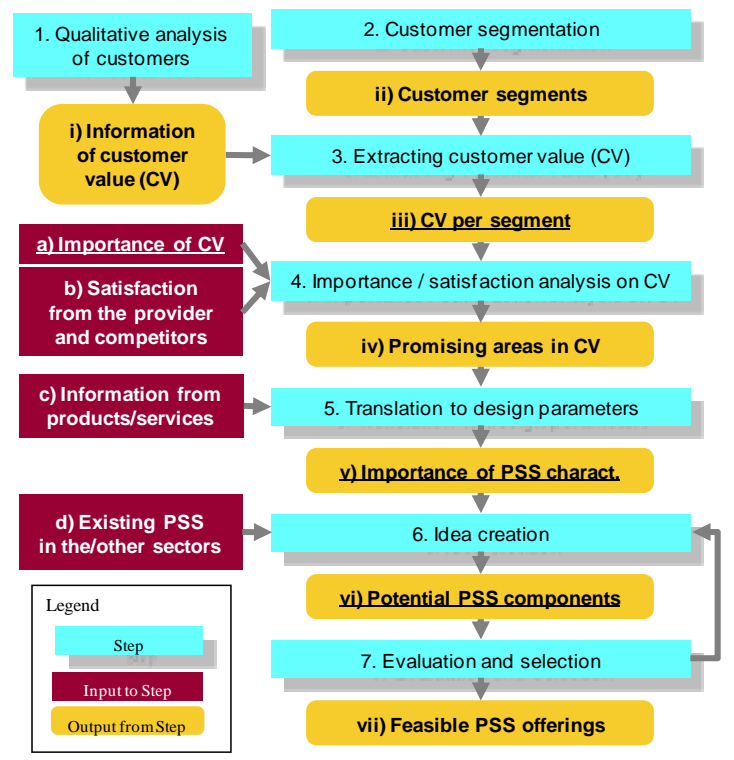

Figure 1. The steps of the entire PSS design method (modified from [6]). Not all iterative processes are shown for simplicity. The underlined items are utilized in the evaluation method in Step 7.

\subsection{PSS evaluation method}

The proposed evaluation method is for Step 7 and should derive an optimized set of PSS components in an offering from the viewpoints of a provider or a customer. This article focuses on the viewpoint of a customer, and a derived offering should maximize the value under the given budget of the customer. The method takes the following six items as inputs.

The first three items are obviously needed. If the utility or value level for each PSS component for a customer were available, the question would be answered with the information of the three items. In real practice this is not the case, especially where there are a large number of PSS components to be selected from. As the fourth and fifth items are available (from a) and v) in Figure 1, respectively) in the PSS design method, adding only the sixth item would enable us to evaluate the PSS components. Note that all the vectors are row vectors.

1. A vector of PSS components (vi) in Figure 1$)$ : $\mathbf{m}=\left(\mathrm{m}_{1}, \ldots, \mathrm{m}_{\mathrm{k}}\right)$.

2. Budget of a customer: $p_{\max }$.

3. Price (vector) of each PSS component: $\mathbf{p}=\left(\mathrm{p}_{1}, \ldots, \mathrm{p}_{\mathrm{k}}\right)$.

4. Importance (vector) of CV (a) in Figure 1): $\mathbf{r}=\left(\mathrm{r}_{1}, \ldots, \mathrm{r}_{\mathrm{l}}\right)$, where $0 \leq \mathrm{r}_{\min } \leq \mathrm{r}_{\mathrm{i}} \leq \mathrm{r}_{\max }$ and $\mathrm{CV}$ (vector): $\mathbf{v}=\left(v_{1}, \ldots, v_{l}\right)$.

This method measures the importance of a CV to quantify a level of the $\mathrm{CV}$, assuming the possibility to add importance of different $\mathrm{CV}$ in an offering.

5. Correlation (matrix) of CV with PSS characteristics: A, where $0 \leq a_{i, j}, 1 \leq i \leq l, 1 \leq j \leq n, \sum_{j=1}^{n} a_{i, j}=1$, and PSS characteristics: $\mathbf{h}=\left(\mathrm{h}_{1}, \ldots, \mathrm{h}_{\mathrm{n}}\right) . \mathbf{A}$ is produced from the matrix of CV with PSS characteristics used in Step 5 (using the QFD based technique) through normalization.

6. Correlation (matrix) of PSS characteristics with PSS components (these components are not necessarily collectively exhaustive unlike Phase II of conventional QFD for a product): $\mathbf{B}$ of size $\mathrm{n} \times \mathrm{k}$, where an element $b$ is an integer between 0 and 10. $b$ represents co relational strength between a characteristic with a component; e.g. a PSS characteristic 'time for preventive maintenance' can have a moderate degree - 5 - with a PSS component 'remote inspection'. 'Operator skill' can be highly - 8 - related to 'training service'. The alternatives, $0, \ldots, 10$ are useful to discriminate subtle differences in components (e.g. 'remote service' and 'remote service extended' in Table 2).

The evaluation method consists of the following four steps.

\section{Step I. Collecting information}

The information for $p_{\max }$ and $\mathbf{p}$ is collected from the sales function of the provider. B is created by the design division. Then, the correlation of $\mathrm{CV}$ with components, $\mathbf{C}$, is calculated as: $\mathbf{C}=\mathbf{A} \cdot \mathbf{B}$

\section{Step II. Determining objective function}

The objective function used in Step III can be determined as follows. The value level can be used with a constraint of a set price limit that cannot be exceeded, i.e. the budget of a customer, $p_{\max }$. The value level gained per monetary unit spent can be chosen for investment efficiency as well.

\section{Step III. Deriving optimized PSSOs}

Using only the value level, the optimization problem may be expressed as:

Maximize the value level of an PSSO: $\mathrm{f}(\boldsymbol{o})=\mathbf{u} \cdot \boldsymbol{o}^{\boldsymbol{T}}$,

where: An PSSO is Vector $\boldsymbol{o}$ of size k, corresponding to $\mathbf{m}$, where an element $o$ has either value 0 or 1 ,

Value level of PSS components: $\mathbf{u}=\mathbf{r} \cdot \mathbf{C}$,

subject to: $\mathbf{p} \cdot \boldsymbol{o}^{T} \leq \mathrm{p}_{\max }$

The investment efficiency of an PSSO $\boldsymbol{o}$ is formulated as $\mathrm{f}(\boldsymbol{o}) /$ $\mathbf{p} \cdot \boldsymbol{o}^{T}$ and may be used as another objective function for the optimization above.

\section{Step IV. Feedback to idea creation}

Two types of useful information are fed back to Step 6 (idea creation). First, such a CV as is addressed by no PSS components, which is expressed as below, can be brought back as an open, and thus promising, $\mathrm{CV}$ for new offerings. 


\section{If $\forall i \in(1, \ldots, l), c_{i, j}=0$, then $v_{j}$ is a promising CV.}

Second, such characteristics as have no correlation with any component can be discovered. These are 'internal' parameters of either the provider or the customer as below.

If $\forall j \in(1, \ldots, k), b_{i, j}=0$, then $h_{i}$ is an 'internal' parameter.

For instance, the geographical distance to the customer's site is not influenced by any PSSO, but depends on the provider's internal factors. Extrinsic motivation of operators at a customer can be influenced only through the customer. This information could be useful in the idea creation in a broader sense, since it can support ideas for improving the internal factors at the provider or the customer. For instance, by launching a base of service technicians at a closer location with the provider's own investment the distance can be decreased, contributing to higher customer value.

\section{Application to a real life case}

\subsection{Target company and its strategies}

This company provides a kind of production machine to customers who produce products using additional contents. The machines can be characterized as investment machines, are quite complex with ICT control, and have a significant cost.

It should be emphasized that this company has strategically shifted to PSS provider role and has begun to increase its focus on services for its customers. It has also established an efficient service organization with modern tools to supply customized services in combination with the machines to offer an optimal solution for the customer. The service activities range from maintenance and supplying spare parts to full service contracts and online services using ICT technologies.

This company, in fact, regards the following three types as the crucial set of instruments to provide customers with value: the physical product, the communication infrastructure, and the service contents. Yet, they lacked a systematic method to develop and evaluate PSSOs at an early stage of development.

\subsection{Results of application}

Steps 1 to 6 of the entire PSS design method were first applied in this application. Obtained through this was the $12 \mathrm{CV}$ (Vector $\mathbf{v}$ ) with relative importance $(\mathbf{r})$, where $r_{\min }$ and $r_{\text {max }}$ were 1 and 7, respectively. CV included 'quality of final product' (importance 6.8) and 'machine/system flexibility' (5.4). 141 PSS characteristics were described (Vector h) (e.g. 'time for set up' and 'response rate of logistics') and they varied significantly in their importance. Table 1 shows Matrix $\mathbf{A}^{\mathbf{T}}$. As Vector $\mathbf{m}, 59$ PSS components were described (only from PSSOs of the company existing on the market) in Step 6. Step 7 was carried out as follows.

Table 1

Normalized correlation of CV with PSS characteristics (Matrix $\mathbf{A}^{\mathrm{T}}$ ).

\begin{tabular}{|c|c|c|}
\hline $\begin{array}{l}\text { PSS Characteristics } \\
\text { PStomer Value } \\
\left(h_{l}, \ldots, h_{141}\right)^{T}\end{array}$ & 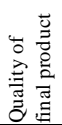 & 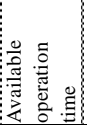 \\
\hline Time for setup & 0.00 & 0.05 \\
\hline Frequency of preventive maintenance & 0.00 & 0.04 \\
\hline Time for preventive maintenance & 0.00 & 0.00 \\
\hline Speed of discovery & 0.00 & 0.04 \\
\hline Speed of problem solving & 0.00 & 0.04 \\
\hline Time for training operator & 0.00 & 0.02 \\
\hline Technician availability & 0.00 & 0.01 \\
\hline Total & 1.00 & 1.00 \\
\hline
\end{tabular}

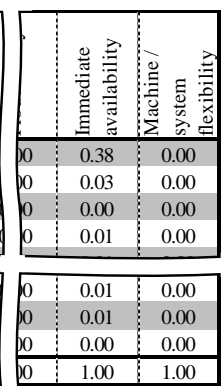

\section{Step I. Collecting information}

$\mathrm{p}_{\max }$ and $\mathbf{p}$ were collected from the internal sales team. In this application, different budgets, 300, 400, 500, and 800 (all in a monetary unit), were set to derive optimal offerings. The matrix $\mathbf{B}$ was given by support of the design team as shown in Table 2 . The transpose of the resulting matrix, $\mathbf{C}^{\mathbf{T}}$, is shown in Table 3.

Table 2

Correlations of PSS characteristics with PSS components (Matrix B).

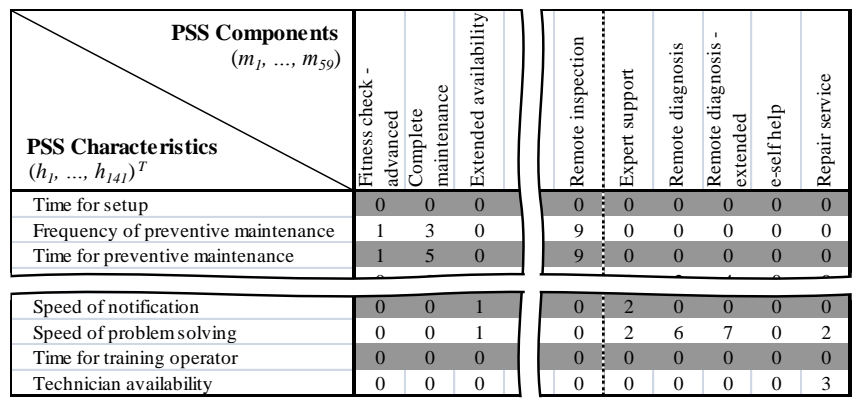

Table 3

Marginal contribution to customer value of PSS components (Matrix $\mathbf{C}^{\mathrm{T}}$ ).

\begin{tabular}{|c|c|c|c|c|c|}
\hline $\begin{array}{r}\begin{array}{r}\text { Customer Value } \\
\left(v_{1}, \ldots, v_{l 2}\right)\end{array} \\
\text { PSS Components } \\
\left(m_{1}, \ldots, m_{59}\right)^{T}\end{array}$ & 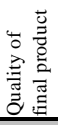 & 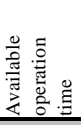 & & 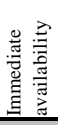 & 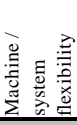 \\
\hline Fitness check - advanced & 0.18 & 0.31 & & 0.32 & 0.00 \\
\hline Complete maintenance & 0.18 & 0.40 & & 0.41 & 0.00 \\
\hline Extended availability & 0.00 & 0.24 & & 0.07 & 0.00 \\
\hline Remote inspection & 0.10 & 0.45 & & 0.41 & 0.00 \\
\hline Expert support & 0.00 & 0.38 & & 0.11 & 0.00 \\
\hline Remote diagnosis & 0.00 & 0.65 & & 0.20 & 0.00 \\
\hline Remote diagnosis - extended & 0.00 & 0.72 & & 0.22 & 0.00 \\
\hline e-self help & 0.01 & 0.06 & & 0.04 & 0.00 \\
\hline Repair service & 0.00 & 0.11 & & 0.03 & 0.00 \\
\hline
\end{tabular}

Step II. Determining objective function and Step III. Deriving an optimized PSSO

The first type of objective function, namely the value level, was chosen to be utilized. The calculation was made using a spreadsheet program using the simplex algorithm as well as the branch and bound algorithm. Derived are the solutions shown in Table 4. For instance, with the budget of 300, the optimized solution includes 'remote inspection' and 'expert support' (the price and the value level were 286 and 68, respectively). If the budget is increased to 400 , the optimized solution also includes 'remote diagnosis'. In the case of 500, 'complete maintenance' gets included and 'remote diagnosis' excluded. The column furthest to the right shows the investment efficiency of the offering, although this is not utilized in this optimization.

Table 4

Derived PSSOs depending on the given budgets.

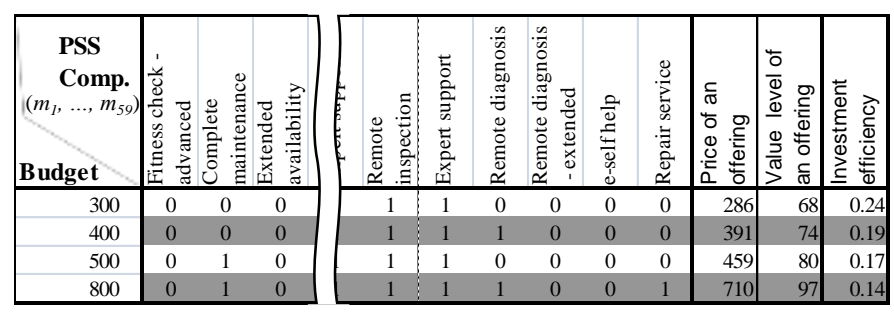

Step IV. Feedback to idea creation

As the first type, for instance, 'machine/system flexibility' was fed back as a promising CV. An example of the second type was the skill of a service technician of the provider, which could 
support the idea of increasing the level of training of internal service technicians.

\subsection{Verification}

As shown in Section 4.2., the newly-proposed method worked to derive effective solutions. The only input from outside of the firm was Vector $\mathbf{r}$ of $12 \mathrm{CV}$, which was feasible to ask a number of customers through a questionnaire. The company expressed high practical usefulness of, and interest in, this method. The time to create $\mathbf{B}$ was not perceived as a problem, since 102 characteristics out of 141 were 'internal' parameters and only 39 had to be correlated with a positive figure to components. It should be also noted that the efforts to create matrixes will even decrease in subsequent attempts. Thus, the additional efforts for this method within the comprehensive PSS design method are found to be low.

The lists of CV, PSS Characteristics, and PSS Components were also found effective to produce meaningful outcomes. Only a part was specific to the example, while others can be reused to other PSS. This ontology issue will be tackled in the future.

The assumption of the method regarding the possibility to add importance of different CV (as mentioned in Section 3.2) will be investigated more in the future as to where it is valid.

\section{Discussion}

Section 4 showed that the proposed method can support evaluation of different PSS components and identification of appropriate solutions in practice once the necessary information is available. To a certain extent, this method is capable of substituting a customer utility analysis. Alternatively, it can be used to verify results from such analysis or to help reduce any type of bias that may be created through other methods of utility analysis.

It should be emphasized that the information created for this purpose was only the correlation of PSS characteristics with PSS components except for the monetary information, which is needed anyway for this economic evaluation. The other information was imported from design information of the PSSO. In addition, that information reutilized from the preceding steps is not peculiar to this PSS design method. In other words, the importance of customer value is fundamental to any PSS design, and the correlation of customer value with PSS characteristics is available if QFD is conducted.

This easy-to-learn and implement method is useful serving as systematic support to evaluate various potential PSSOs. Its advantages are its simplicity and quickness; it can be performed with e.g. a pen and paper or with spreadsheet software. To make it even more practical, the intention is to create spreadsheet based software that supports the entire process, e.g. calculations as well as documentation of the results. Highlighted features are also in line with the general principles a design support method should fulfil in order to become utilized in industry [14]: (1) be easy to adopt and implement; (2) facilitate developers to fulfil specified requirements on the presumptive offering; (3) reduce the risk that important elements in the development are forgotten; (4) reduce the total calendar time (from start to end) to solve the task.

One of the scientific newness of this method exists in that it builds on the levels for value provided without questioning the customers on value levels for individual offerings. This is especially an advantage when there are a large number of PSS components to choose from, which makes it virtually impossible in practice to ask customers. This method can address a large number of components; in such a case, it can provide more information as its result than conjoint analysis.
To improve the preciseness of the estimated utility level, investigation of the possibility to adopt a parameter other than the importance of CV will be a future subject of research. Another in-depth question about this measurement is if the utility level of an offering can be over (or below) the summation of the utility level of each component in the offering. This question is motivated as there might be positive (or 'negative') synergy by combining multiple components in terms of the total utility.

Finally, the current proposed method focuses on the viewpoint of customer. It does not cover the provider's cost evaluation for providing PSSOs or the evaluation of the trade off between the customer's value and the provider's cost (PC) for providing; the future version will manage that. In other words, the new method will support decisions, e.g. whether to develop a durable product (higher PC) that will cause fewer failures during use (higher CV and lower PC, e.g. service) or a 'normal' product (normal PC) that will cause a 'normal' amount of failures during use (normal CV and PC).

\section{Conclusion}

This article proposed a new method for evaluating PSSOs. It improves formulation of an evaluation step within an existing comprehensive method for designing a PSS. To a certain extent, this method is capable of replacing a customer utility analysis. Its primary advantage is the effective utilization of design information accumulated at the earlier part of the comprehensive method, as opposed to marketing-oriented methods solely for utility measurement (e.g. conjoint analysis). Future works include incorporating the provider's viewpoint as discussed in Section 5 and verifying this method further with more cases.

\section{Acknowledgements}

The authors would like to express special gratitude to the anonymous company for their active cooperation. Our gratitude is extended to Mr. Jens Mündler from Darmstadt Univ. of Technology, Prof. Tamio Arai and Dr. Tatsunori Hara from the Univ. of Tokyo, and Prof. Yoshiki Shimomura from Tokyo Metropolitan Univ. for their cooperation in the application.

\section{References}

[1] Meier, H., Roy, R., Seliger, G., 2010, Industrial Product-Service Systems - IPS ${ }^{2}$, Annals of the CIRP, 59/2:607-627.

[2] Boothroyd, G., Alting, L., 1992, Design for Assembly and Disassembly, Annals of the CIRP, 41/2:625-636.

[3] Aurich, C., Fuchs, C., DeVries, F., 2004, An Approach to Life Cycle Oriented Technical Service Design, Annals of the CIRP, 53/1:151-154.

[4] Meier, H., 2004, Life Cycle-Based Service Design for Innovative Business Models Annals of the CIRP, 53/1:393-396.

[5] Komoto, H., Tomiyama, T., 2008, Integration of a service CAD and a life cycle simulator, Annals of the CIRP, 57/1:9-12

[6] Sakao, T., Birkhofer, H., Panshef, V., Dörsam, E., 2009, An Effective and Efficient Method to Design Services: Empirical Study for Services by an Investmentmachine Manufacturer, International Journal of Internet Manufacturing and Services, 2/1:95-110.

[7] Sakao, T., Lindahl, M., Eds., 2009, Introduction to Product/Service-System Design, Springer, London.

[8] Arai, T., Shimomura, Y., 2005, Service CAD System - Evaluation and Quantification, Annals of the CIRP, 54/1:463-466.

[9] Akao, Y., 1990, Quality Function Deployment, Productivity Press, Portland, OR.

[10] Pahl, G., Beitz, W., 1996, Engineering Design: A Systematic Approach, SpringerVerlag, London.

[11] Tseng, M. M., Jiao, J., Merchant, M. E., 1996, Design for Mass Customization, Annals of the CIRP, 45/1:153-156.

[12] Zeithaml, V. A., 1988, Consumer Perceptions of Price, Quality, and Value: A Means-End Model and Synthesis of Evidence, Journal of Marketing, 52/3:2-22.

[13] Green, E., Srinivasan, V., 1978, Conjoint Analysis in Consumer Research: Issues and Outlook, Journal of Consumer Research, 5/2:103-123.

[14] Lindahl, M., 2005, Engineering Designers' Requirements on Design for Environment Methods and Tools, Ph. D. Thesis, Industrial Engineering and Management, KTH (Royal Institute of Technology), Stockholm. 